\title{
The Interlaminar Toughness of Carbon-Fibre Reinforced Plastic Composites using 'Hybrid-Toughened' Matrices
}

\author{
A.J. Kinloch, R. D. Mohammed and A.C. Taylor \\ London SW7 2AZ, UK. \\ S.Sprenger \\ Hanse Chemie AG, Charlottenburger Str. 9, 21502 Geesthacht, Germany \\ D.Egan
}

Department of Mechanical Engineering, South Kensington Campus, Imperial College London,

Noveon Inc., 9911 Brecksville Rd., Cleveland, OH, 44141, USA

(a.kinloch@imperial.ac.uk)

Key words: composites, epoxy polymers, interlaminar toughness, nano-materials, rubber-toughened.

\section{Introduction}

When polymerised, epoxy polymers are amorphous and highly-crosslinked (i.e. thermosetting) materials. This microstructure results in many useful properties for structural engineering applications, such as a high modulus and failure strength, low creep, and good performance at elevated temperatures. For these reasons, epoxy polymers are frequently used as the matrices for fibre-reinforced materials.

However, the structure of such thermosetting polymers also leads to one highly undesirable property in that they are relatively brittle materials, with a poor resistance to crack initiation and growth. Nevertheless, it has been well established for many years that the incorporation of a second micro-phase of a dispersed rubbery [e.g. 1-4] or a thermoplastic polymer [e.g. 5-7] into the epoxy can increase their toughness, without significantly impairing the other desirable engineering properties; and, considering the incorporation of a rubbery phase, typically the rubber particles are about 1 to $5 \mu \mathrm{m}$ in diameter with a volume fraction of about 5 to $20 \%$. More recently there has emerged a new technology which holds great promise for increasing further the mechanical performance of such multiphase thermosetting polymers. Namely, via the additional formation of a nano-phase structure in the polymer, where the nano-phase consists of small rigid particles of 
silica [8, 9] to give 'hybrid-toughened' epoxy polymers. This has been shown to not only increase further the toughness of the epoxy polymer but also, due to the very small size of the silica particles, not to lead to a significant increase in the viscosity of the epoxy. Both of these exciting and novel properties make the 'hybrid-toughened' epoxy polymers ideal matrices for relatively tough composite materials which may be produced by resin-transfer moulding (RTM), vacuumassisted resin-transfer moulding (VARTM), etc. low-cost manufacturing processes. The initial results from such carbon-fibre reinforced-plastic (CFRP) composite materials produced via a VARTM process are reported in the present letter.

\section{Experimental}

\subsection{Materials}

The materials were based upon a one-component hot-cured epoxy formulation. The epoxy resin was a standard diglycidyl ether of bis-phenol A (DGEBA) with an epoxy equivalent weight (EEW) of 185 g/mol, 'Bakelite EPR 164' supplied by Hexion Speciality Chemicals, Duisberg, Germany. The nano-particles of silica $\left(\mathrm{SiO}_{2}\right)$ were obtained at a concentration at $40 \mathrm{wt}$ \% in this DGEBA epoxy resin: 'Nanopox F400' from hanse chemie, Geesthacht, Germany. The surfacemodified $\mathrm{SiO}_{2}$ nano-particles had an average particle size of about $20 \mathrm{~nm}$, with a narrow range of particle-size distribution. This particle size of about $20 \mathrm{~nm}$ is created during a sol-gel manufacturing process [10], whereby the silica particles are formed in-situ, and the particle size and excellent dispersion of these $\mathrm{SiO}_{2}$ particles remain unchanged during any further mixing and/or blending operations. Further, despite the relatively high $\mathrm{SiO}_{2}$ content of 40 wt.\%, the nanofilled epoxy resin still has a comparatively low viscosity due to the agglomerate-free colloidal dispersion of the nano-particles of $\mathrm{SiO}_{2}$ in the epoxy resin. The small diameter and good dispersion of the nano-particles of silica have been previously reported and shown $[8,9]$.

The reactive liquid rubber, which gives rises to the micrometre-sized spherical rubber particles upon curing of the formulation, was a carboxyl-terminated butadiene-acrylonitrile (CTBN) rubber. It was supplied by Noveon, Cleveland, USA, and was 'Hycar CTBN 1300x8' with a number-average molecular weight of 3,550 g/mol and an acrylonitrile content of 18wt.\%. This was pre-reacted with the DEGBA resin to give a 40 wt.\% CTBN-epoxy adduct: 'Albipox 1000' from hanse chemie, Geesthacht, Germany. The curing agent was an accelerated methylhexahydrophthalic acid anhydride, namely 'Albidur HE 600' supplied by hanse chemie, Geesthacht, Germany. 
To determine the properties of the matrices, the formulations were cured by firstly mixing together the simple DGEBA epoxy with given amounts of the nano- $\mathrm{SiO}_{2}$ epoxy and CTBN-epoxy adduct, to give the required levels of added nano- $\mathrm{SiO}_{2}$ and $\mathrm{CTBN}$ rubber. The value of the EEW of the blend was then measured, via titration, and the stoichiometric amount of the curing agent was added to the mixture, which was poured into release-coated moulds and cured for 1 hour at $90^{\circ} \mathrm{C}$, followed by a post-cure of 2 hours at $160^{\circ} \mathrm{C}$.

The CFRP composite panels were manufactured by vacuum-assisted resin-transfer moulding (VARTM). The carbon fibre was an isotropic linen-weave fibre fabric arranged in a $0 / 90^{\circ}$ pattern with a density of $168 \mathrm{~g} / \mathrm{m}^{2}$ and supplied by Lange-Ritter, Gerlingen, Germany. The average volume fraction of the fibres in the CFRPs was $26.5 \%$. A thin film of poly(tetrafluoroethylene) (PTFE) was inserted into the fabric prior to resin infusion, along one side of the CFRP plate to a length of $35 \mathrm{~mm}$, to act as a starter crack for the fracture specimens. It again should be emphasised that the lack of any significant increase in the viscosity of the epoxy resin, containing even 10.5 wt.\% of the nano-silica, enabled this range of resins to be readily used in a VARTM manufacturing process.

\subsection{Mechanical and Thermal Properties of the Bulk Matrices}

The glass transition temperature, $T_{g}$, of the various formulations was measured using differential scanning calorimetry at a rate of $10^{\circ} \mathrm{C} /$ minute. The stress-intensity factor, $K_{I c}$, at the onset of crack growth was measured according to the ISO test method [11]. The coefficient of variation in the values of $K_{I c}$ was $\pm 22 \%$. The modulus, $E$, was measured at a displacement rate of $1 \mathrm{~mm} / \mathrm{min}$ from uniaxial tensile tests, according to the ISO test method [12,13]. The value of the fracture energy, $G_{I c}$, was calculated from a knowledge of the values of $K_{I c}$ and $E$, using the relationship:

$$
K_{I c}^{2}=\frac{E G_{I c}}{1-v^{2}}
$$

where $v$ is the Poisson's ratio and was taken to be 0.35 in value.

\subsection{Mechanical Properties of the Carbon-fibre Reinforced-plastic Composites}

Double cantilever beam (DCB) specimens were used to measure the interlaminar fracture energy, $G_{I c}$ (interlaminar), under Mode I loading conditions according to the ISO test method [14]. The coefficient of variation in the values of $G_{I c}$ (interlaminar) was typically $\pm 10 \%$. The flexural 
modulus of the CFRP plates was measured according to the ASTM test method [15], at a constant strain rate of $0.01 \mathrm{~min}^{-1}$.

\section{Results}

\subsection{The Nano-silica Phase and Rubber-phase (i.e. 'Hybrid') Toughened Matrices}

The results for the epoxy polymers containing both a nano-silica and a rubbery phase are shown in Table 1. We may firstly compare the data for the pure epoxy polymer, containing no toughening phase, to that of the epoxy polymer containing only the CTBN-adducted rubbery particles, see Table 1. (The rubbery particles are produced via a reaction-induced phase-separation, giving particles of about 1 to $2 \mu \mathrm{m}$ in diameter, as is well documented for such materials [1-4].) As expected the modulus, $E$, of the epoxy polymer decreases with the addition of the CTBN rubber and the decrease in the value of the $T_{g}$ indicates that some of the rubber remains dissolved in the epoxy-polymer phase. Of course, these relatively minor changes in these properties of the rubbertoughened epoxy polymer are more than compensated for by the significant increases in the values of $K_{I c}$ and $G_{I c}$. Indeed, the value of $G_{I c}$ increases from about $100 \mathrm{~J} / \mathrm{m}^{2}$ to over $400 \mathrm{~J} / \mathrm{m}^{2}$ due to the toughening mechanisms induced by the presence of the rubbery particles. Thus, compared with the pure epoxy polymer, with no dispersed rubbery phase, the rubbery particles greatly increase the toughness of the material via interactions of the stress field ahead of the crack tip and the rubbery particles which leads to greatly enhanced plastic deformation of the epoxy matrix [2-4,16].

Secondly, we may consider the effects of introducing both rubbery micrometre-sized particles and nano-SiO 2 particles into the epoxy polymer, to give a multiphase 'hybrid-toughened' polymeric material. There are no significant major changes in the $T_{g}$ of the epoxy polymer containing 9wt.\% CTBN and the various concentrations of the nano- $\mathrm{SiO}_{2}$ particles, which suggests that the volume fraction of the rubbery-particulate phase which has formed is independent of the concentration of the nano-silicate phase present. Considering the modulus of the bulk epoxy material, the addition of $11.2 \mathrm{wt} \%$. of the silica nano-phase to the pure epoxy polymer increases the value of the modulus from 2.96 GPa to $3.63 \mathrm{GPa}$, see the results shown in Table 1. Also, as would be expected, the modulus, $E$, of the rubber-particulate epoxy polymer increases steadily from 2.44 GPa as the wt.\% of the silica nano-phase is increased, again see the results shown in Table 1. However, it is noteworthy that the addition of the nano-silica phase to the rubber-particulate epoxy polymer never leads to a full recovery of the modulus, if the 'hybrid' polymers are compared with the pure epoxy polymer. However, the most dramatic changes in the mechanical properties are the very significant increases in the values of $K_{I c}$ and $G_{I c}$. Indeed, the value of $G_{I c}$ increases from about 
$100 \mathrm{~J} / \mathrm{m}^{2}$ for the pure epoxy polymer to over $1200 \mathrm{~J} / \mathrm{m}^{2}$ upon the formation of the 'hybrid' material containing both rubbery micrometre-sized particles and 10.5 wt.\% nano- $\mathrm{SiO}_{2}$ particles. The major increases in the toughness of the 'hybrid-toughened' epoxy polymers as the concentration for the nano-phase is increased may clearly be seen from the data in Table 1.

\subsection{The Carbon-Fibre Reinforced-Plastic Composites}

The corresponding results for the CFRP laminates are shown in Table 2. As would be expected, the modulus, $E$, of the CFRP laminates is essentially dominated by the presence of the carbon-fibre weave. Indeed, whilst the very minor influence of the nano-silica particles in increasing the modulus of the bulk epoxy polymers (see Table 1) is evident in the modulus values for the composite laminates, as may be seen from the modulus data given in Table 2, a value of $E$ for all the CFRP laminates of approximately 26 GPa is recorded.

Considering the values of $G_{I c}$ (interlaminar), the presence of the nano- $\mathrm{SiO}_{2}$ particles alone (at a concentration of $11.9 \mathrm{wt}$ \%) has no significant effect on the delamination resistance, whilst the addition $9 \mathrm{wt} \%$ of CTBN rubber alone does lead to an increase in the toughness from 439 to 1050 $\mathrm{J} / \mathrm{m}^{2}$. However, the further addition of nano- $\mathrm{SiO}_{2}$ particles to the rubber-toughened matrix, giving a range of 'hybrid-toughened' epoxy matrices, gives a further enhancement of the toughness, with a highest value of $G_{I c}\left(\right.$ interlaminar) of $1320 \mathrm{~J} / \mathrm{m}^{2}$ being recorded.

The relationship between the values of $G_{I c}$ (interlaminar) of the CFRP laminates and $G_{I c}$ of the bulk matrices is shown in Figure 1. (Note that the wt.\% of the nano- $\mathrm{SiO}_{2}$ particles stated is the average value for some of the formulations given in Tables 1 and 2, since an exact correspondence between the composite and bulk matrix tests was not always experimentally obtained.) The results given in this figure clearly reveal the significant toughening of both the composite and bulk materials by the CTBN-rubbery phase being present in the epoxy polymer; and the further enhanced values of $G_{I c}$ (interlaminar) and $G_{I c}$ of the bulk matrices when the 'hybrid-toughened' epoxy polymers are employed. Thus, the synergistic effect of having a multiphase structure based upon both nano-SiO 2 particles and micro-sized rubbery domains is clearly demonstrated.

\section{Conclusions}

The use of nano- $\mathrm{SiO}_{2}$ particles and rubbery particles to give 'hybrid-toughened' epoxy polymers has been demonstrated to give a range of very novel matrices which lead to an increased delamination toughness of the resulting carbon-fibre reinforced-plastic (CFRP) composites. Also, 
it is noteworthy, that the presence of even a relatively high concentration of the nano- $\mathrm{SiO}_{2}$ toughening particles does not lead to a decrease in the modulus of the composite. Nor do such particles lead to a significant increase in the viscosity of the epoxy resin, which would preclude the use of low-cost manufacturing routes, such as a vacuum-assisted resin-transfer moulding (VARTM) process. Future work will explore the detailed mechanisms of toughening which are initiated by the nano- $\mathrm{SiO}_{2}$ particles. Since, the understanding of these mechanisms may lead to even further increases in the mechanical performance of 'hybrid-toughened' epoxy polymers, containing a complex multiphase structure of nano- and micro-sized phase inclusions, and such increases may again be transferable to fibre-composite materials produced by relatively low-cost manufacturing routes. 


\section{Acknowledgments}

The authors wish to thank the Royal Academy of Engineering for a Post-Doctoral Research Fellowship and the Royal Society for a Brian Mercer Postdoctoral Award for Innovation for Dr. A.C. Taylor and a studentship from the Government of Trinidad \& Tobago for Mr. R.D. Mohammed. Also, they would wish to acknowledge the general support from the US Army European Research Office for Mr. R.D. Mohammed.

\section{References}

1. $\quad$ R.S. DRAKE and A.R. SIEBERT, SAMPE Quart. 6 (4) (1975) 11.

2. A.J. KINLOCH, S.J. SHAW, D.A. TOD and D.L. HUNSTON, Polymer 24 (1983) 1341.

3. $\quad$ A.F. YEE and R.A. PEARSON, J. Mater. Sci. 21 (1986) 2462.

4. C.A. FINCH, S. HASHEMI and A.J. KINLOCH, Polymer Communications 28 (1987) 322.

5. $\quad$ C.B. BUCKNALL and A.H. GILBERT, Polymer 30 (1989) 213.

6. A.J. KINLOCH, M.L. YUEN and S.D. JENKINS, J. Mater. Sci. 29 (1994) 3781.

7. B.B. JOHNSEN, A.J. KINLOCH and A.C. TAYLOR, Polymer 46 (2005) 7352.

8. A.J. KINLOCH, J.H. LEE, A.C. TAYLOR, S. SPRENGER, C. EGER and D. EGAN, J. Adhesion 79 (2003) 867.

9. A.J. KINLOCH, R.D. MOHAMMED, A.C. TAYLOR, C. EGER, S. SPRENGER and D. EGAN, J. Mater. Sci. 40 (2005) 5083.

10. S. SPRENGER, C. EGER, A.J. KINLOCH, J.H. LEE, A.C. TAYLOR and D. EGAN, Adhäsion, Kleben \& Dichten 3 (2003) 24.

11. ISO-13586, "Plastics-Determination of Fracture Toughness $\left(G_{I c}\right.$ and $\left.K_{I c}\right)$ - Linear Elastic Fracture Mechanics (LEFM) Approach” (ISO, Geneva, 2000).

12. ISO-527-1, "Plastics - Determination of Tensile Properties - Part 1: General Principles" (ISO, Geneva, 1993).

13. ISO-527-2, "Plastics - Determination of Tensile Properties - Part 2: Test Conditions for Moulding and Extrusion Plastics" (ISO, Geneva, 1993).

14. ISO-15024, "Determination of the Mode I Delamination Resistance of Unidirectional Fiber-Reinforced Polymer Laminates Using the Double Cantilever Beam (DCB)”, (ISO, Geneva, 1999).

15. ASTM-D790M-93, "Test Methods for Flexural Properties of Unreinforced and Reinforced Plastics and Electrical Insulating Materials [Metric]”, (ASTM, Philadelphia, 1999).

16. A.J. KINLOCH, Materials Research Society Bulletin 28, (2003) 445. 
Table 1. The formulations employed and the mechanical properties of the epoxy-polymer matrices

\begin{tabular}{|c|c|c|c|c|c|}
\hline \multicolumn{2}{|c|}{ Formulation } & \multirow[t]{2}{*}{$T_{g}\left({ }^{0} \mathrm{C}\right)$} & \multirow[t]{2}{*}{$E$ (GPa) } & \multirow[t]{2}{*}{$K_{I c}(\mathrm{MPa} \sqrt{\mathrm{m}})$} & \multirow{2}{*}{$\begin{array}{c}G_{I c}(\text { bulk }) \\
\left(\mathbf{J} / \mathbf{m}^{2}\right)\end{array}$} \\
\hline wt. \% nano-SiO & wt.\% CTBN & & & & \\
\hline 0.0 & 0.0 & 143 & 2.96 & 0.59 & 103 \\
\hline 11.2 & 0.0 & 142 & 3.63 & 1.23 & 363 \\
\hline 0.0 & 9.0 & 126 & 2.44 & 1.11 & 443 \\
\hline 2.3 & 9.0 & 133 & 2.66 & 1.71 & 964 \\
\hline 4.5 & 9.0 & 135 & 2.77 & 1.70 & 917 \\
\hline 9.0 & 9.0 & 129 & 2.79 & 1.76 & 973 \\
\hline 10.5 & 9.0 & 126 & 2.80 & 1.99 & 1240 \\
\hline
\end{tabular}

Table 2. The formulations employed and the mechanical properties of the CFRP laminates

\begin{tabular}{|c|c|c|c|}
\hline \multicolumn{2}{|c|}{ Formulation } & \multirow[t]{2}{*}{$E(G P a)$} & \multirow{2}{*}{$\begin{array}{c}G_{I c} \\
\text { (interlaminar) } \\
\left(\mathbf{J} / \mathbf{m}^{2}\right)\end{array}$} \\
\hline wt. $\%$ nano-SiO & wt.\% CTBN & & \\
\hline 0.0 & 0.0 & 26.3 & 439 \\
\hline 11.9 & 0.0 & 26.8 & 489 \\
\hline 0.0 & 9.0 & 25.9 & 1050 \\
\hline 2.3 & 9.0 & 26.1 & 1260 \\
\hline 4.7 & 9.0 & 26.1 & 1080 \\
\hline 7.2 & 9.0 & 26.2 & 1110 \\
\hline 10.5 & 9.0 & 26.2 & 1320 \\
\hline
\end{tabular}




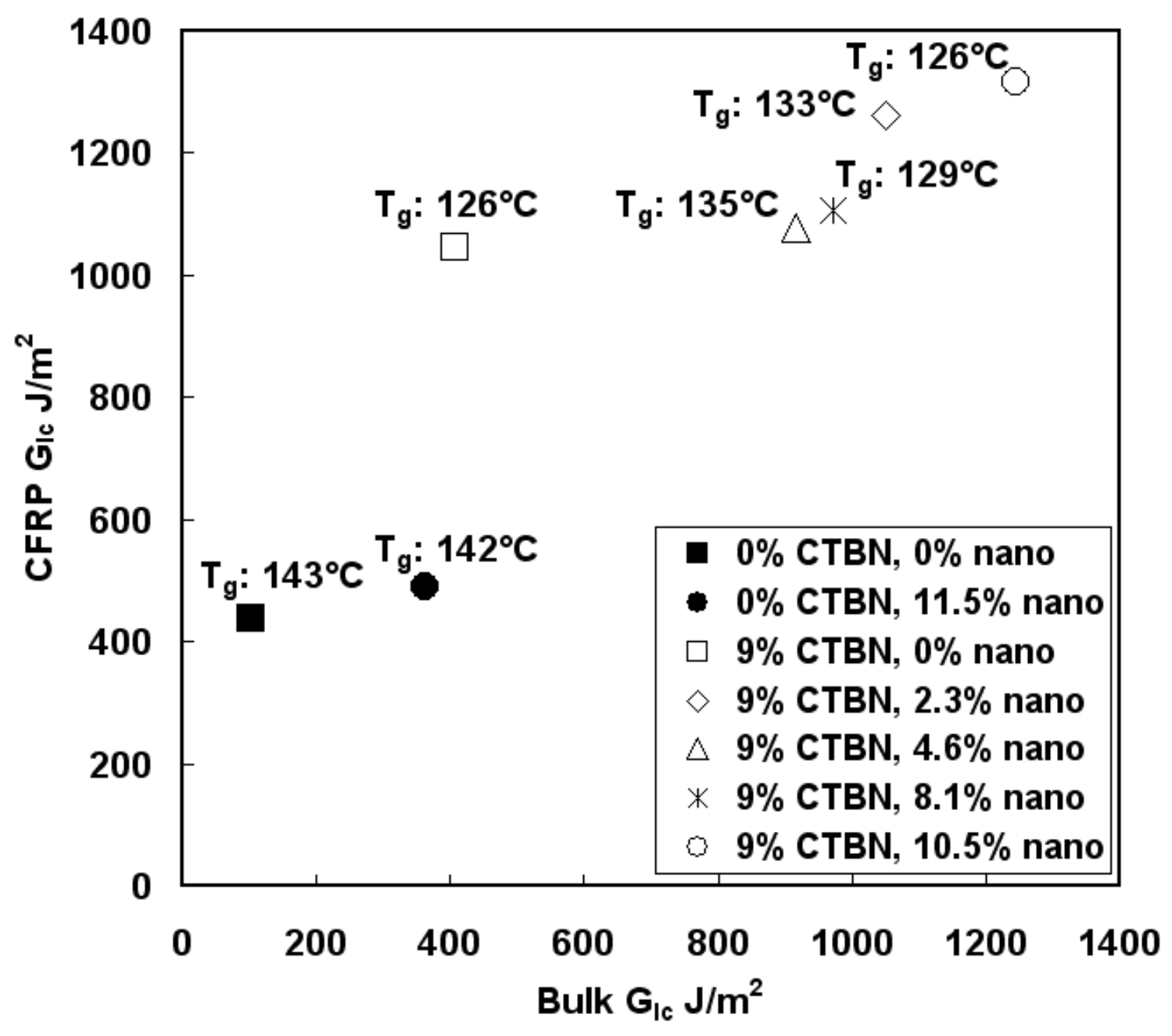

Figure 1. $G_{I c}$ (interlaminar) for the CFRP laminates versus $G_{I c}$ (bulk) for the matrices. Values of the $T_{g}$ for the matrices are also shown. 